\title{
REDISCOVERING JOHN DEWEY'S MODEL OF LEARNING THROUGH REFLECTIVE INQUIRY
}

Yordanka Dimova, Kalina Kamarska

University of Plovdiv "Paisii Hilendarski", Plovdiv, Bulgaria

E-mail: dimova@uni-plovdiv.bg; kamarska@uni-plovdiv.bg

\begin{abstract}
During the $21^{\text {st }}$ century, in the sphere of Science education, there has been an increasing interest in the problem of operationalizing reflection because it's one of the most powerful mechanisms for developing students' thinking and forming key competencies - learning to learn and science literacy. The classical legacy of the American philosopher and pedagogue John Dewey provides a source for valuable ideas for solving this problem.

The goal of this qualitative study is to focus on John Dewey's concept for reflective inquiry as well as on the interpretations of his ideas by other authors. The intention is to merge these interpretations into a whole for two reasons: 1) to reconstruct John Dewey's model for reflective inquiry, 2) to adapt this model to the peculiarities of Science education practice.

To realize this goal, a comparison should be drawn between the meanings of key concepts from Dewey's texts and those in the texts of his followers and reviewers. As a result of this interpretive framework, the authors of this paper abandon the general understanding that the stages of reflective thinking comprise a main component in Dewey's concept for reflective inquiry. The emphasis moves to the connection between reflection and the actions in the course of inquiry. On the basis of reconstructing Dewey's model, the authors suggest ideas for actualizing and activating students' reflection before, during and after completing different types of experiments.
\end{abstract}

Key words: reflection, inquiry-based learning, science education.

\section{Introduction}

In the field of Science education in Dewey's ideas about reflection, action and learning are topical even today. These ideas can be found in the concepts of inquiry-based learning, problem-based learning and experiential learning in the context of the philosophy of constructivism about knowledge. There is a great number of educational theorists and contemporary educators who follow John Dewey's recommendation to study sciences in the way scientists do through inquiry including problem-solving, formulating and testing of hypotheses (Gormally et al., 2009); through active participation of the students in a process of solution-seeking (Barrow, 2006); through resolving problematic situations and building an understanding of the environment and the self (Won, 2009).

There is a great number of contemporary authors who describe reflective inquiry and suggest good ideas about reflective pedagogical practice (see, for example: Rodgers, 2002; Oliver, 2004; Krishnamurthy, 2007; Mason, 2012; Jones \& Jones, 2013; Sahin \& Usta Gezer, 2014 ; etc.). The elaboration of a group of authors deserves special attention because it focuses on the essence of reflective inquiry and its practice in the field of professional education and learning (Lyons, 2010). N. Lyons comments on the ideas about reflection and reflective inquiry of three authors in great detail: J. Dewey, D. Shon and P. Freire. As a result, the focus moves „from reflective inquiry as a kind of thinking, to a kind of knowing in action, to critical reflection for the conscious interrogation of the social, cultural and political contexts of learning"( ibid, p. 4). 
Yordanka DIMOVA, Kalina KAMARSKA. Rediscovering John Dewey's model of learning through reflective inquiry

PROBLEMS

OF EDUCATION

IN THE $21^{\text {st }}$ CENTURY Volume 63, 2015

However, none of them has reconstructed or adapted Dewey's model of reflective inquiry specifically for the purposes of Science education. That is why the task of this interpretive framework is to find the answers to two research questions:

Which are the main ideas about reflective inquiry belonging to Dewey? How can these ideas be applied in Science education?

The supposition that it is possible to reconstruct Dewey's model of reflective inquiry and based on it to create a didactic model which through the mechanisms of reflection can positively influence the process of learning and the knowledge which students gain thanks to their Science education.

The meanings of key terms - situation, inquiry, reflection - are revealed through analysis of texts written by John Dewey's and his reviewers or followers. Mind mapping is used as a main technique for visualizing Dewey's model of reflective inquiry.

Since the reconstructed model includes the methods of observation and experimentation in itself, it is suitable for the purposes of Science education. This makes it possible to emphasize on the actualization of students' reflection before, during or after completing various types of experiments.

It's worth noting that Dewey's model for active learning through reflective inquiry was applied in pedagogical practice throughout $2012 / 2013$ and 2013/2014 with students in the $6^{\text {th }}$ and $7^{\text {th }}$ grade in Bulgarian schools. The results from the pedagogical experiment, measured with the criteria of science literacy have been published accordingly (Kamarska et al., 2014).

\section{John Dewey's Model of Inquiry}

One of the most frequently quoted books by Dewey is „How we think” (originally published in 1910, revised edition - 1933). It outlines a version of Dewey's original model for inquiry in the context of education (Dewey, 1997). Later on this model was developed in the context of scientific knowledge in the book „Logic: The Theory of Inquiry” (Dewey, 1938).

The first element (Figure 1) appropriate for visualizing Dewey's model of inquiry is his definition of inquiry and of situation:

Inquiry is the controlled or directed transformation of an indeterminate situation into one that is so determinate in its constituent distinctions and relations as to convert the elements of the original situation into unified whole." (Dewey, 1938, p. 108; Dewey's italics)

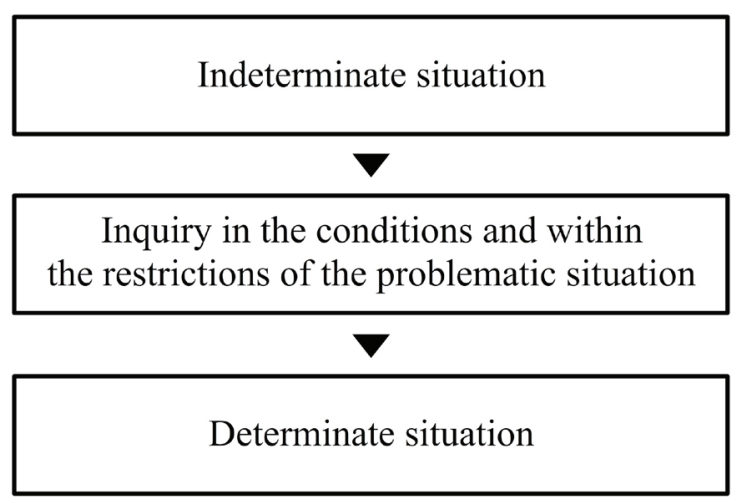

Figure 1: Dewey's definition of inquiry.

According to J. Dewey, the situation is not a separate object or event, or a series of isolated objects or events but rather objects or events which are connected to a contextual whole (Dewey, 1938). The situation "is present as the background and the control of every experience" 
(ibid, p. 76; Dewey's italics). The situation is "agent relative and practice relative" (Brown, $2012,273)$, it is a fragment of a person's experience, a field of clash and interaction of subjective and objective tendencies of experience (Minchev, 2008).

An indeterminate situation is one that is marked by a certain kind of perplexity or difficulty, one that is unclear, uncertain, ambiguous, doubtful, or precarious with respect to what is going on and what is to be done. (Brown, 2012, 275-276)

The problematic situation is indeterminate situation which prompts the individual to inquire in order to make it determinate (Dewey, 1929). Most important in this definition is the goal of the inquiry - transforming the indeterminate situation into a determinate one; the situation is a system-forming factor. Various problems could be inferred from one problematic situation; these problems could in turn lead to various solutions.

The American philosopher Tom Burke distinguishes two dimensions of activity in Dewey's concept of inquiry - "a linear component and a circular component" (Burke, 1994, 158). The linear component of inquiry is the transition from an indeterminate situation into a determinate one through "identification of problem" and "determination of solution" (ibid, 159) (these are in fact the two actual consecutive phases of problematic thinking). According to T. Burke, the circular component of inquiry includes accepting of the possible directions of action and forecasting the expected results from these observations; includes conducting experiments with possible alternatives for testing their applicability, observing the results of their implementation.

The second element (Figure 2) of Dewey's model is the emphasis on thinking during inquiry. The thought (reflective) process is implemented in five logically distinct steps (stages, phases):

"( i) a felt difficulty; (ii) its location and definition; (iii) suggestion of possible solution; (iv) development by reasoning of the bearings of the suggestion; $(v)$ further observation and experiment leading to its acceptance or rejection; that is, the conclusion of belief or disbelief." (Dewey, 1997, p. 72)

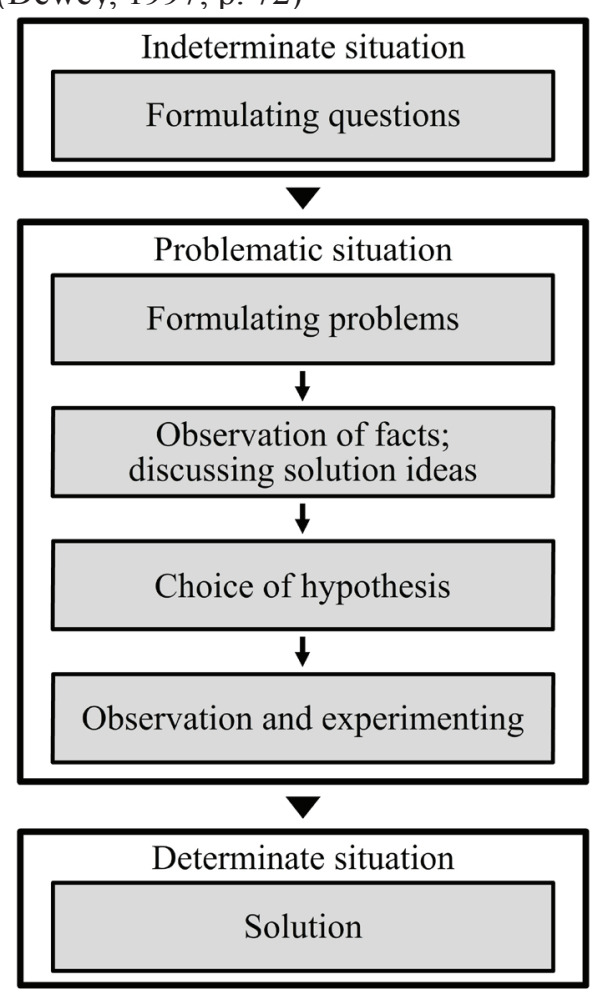

Figure 2: The structure of inquiry (according to J. Dewey). 
PROBLEMS

OF EDUCATION

IN THE $21^{\text {st }}$ CENTURY

Volume 63,2015

The stage of "a felt difficulty" could be related to the arising of questions in the individual when there's a shortage of information in the conditions of an indeterminate situation and its perception as a problematic situation.

The stage of "localizing and defining of the complexity" could be related to the action of defining a problem.

The problem is the partial transition through inquiry of the problematic situation into a determinate situation. The way the problem is thought of defines what concrete suggestions and data could be accepted or rejected. The problem is half-solved when it is clearly defined. The problem relates to concrete observations which lead to ideas for its solution.

The stage of "suggesting a possible solution" relates to discussing ideas - suggestions, assumptions, hypotheses. The possible solution is introduced as an idea from the point of view of the problem which has been established during observation; every idea arises as a suggestion but not every suggestion is an idea; suggestions become ideas when they are tested in relation to their meaning in resolving the problem.

The stage of "development through thinking over the aspects of the assumption" corresponds to the choice of the possible solution in the form of a hypothesis. Facts and the ideas related to them arise and develop accordingly. The more the facts gathered from observation, the clearer the ideas become for the researcher. Facts are a test for ideas. Ideas prompt and direct to further actions of observation; they are assumptions and plans which lead to discovering new facts and to organizing them into a unified whole.

After developing possible solutions and after choosing one of them, it is necessary "to observe and experiment". Actions and operations which establish new facts need to be carried out; the new facts need to correspond to the hypothesis in order to check whether the ideas work well. The new facts are connected to some of the facts received in advance or the relation to other known facts is dismissed, that is, facts are re-arranged. If the hypothesis is confirmed, then it is assumed that the way of action is accurate.

During the re-arrangement a shift of the idea (or hypothesis) might become necessary which in turn will require new observations, facts re-arrangement, etc., until a unified and complete system of facts is achieved. Sometimes negative results from the check of the hypothesis might hint what changes are required in the hypothesis in order to move on with the inquiry in the new direction.

The objective and final product of inquiry is a judgment...

A judgment that satisfies the conditions of good inquiry and can be used as a settled means to future inquiry has the property of warranted assertability. (Brown, 2012, p. 280; Brown's italics).

In the article "Professor Dewey's Analysis of Thinking" L. Buermeyer publishes critical notes related to John Dewey's concept of inquiry (Buermeyer, 1920). According to this author, the five steps of the thought process described in "How We Think" do not fully reflect the complexity of scientific inquiry.

In response to this critique J. Dewey points out in "An Analysis of Reflective Thought" that the steps of the inquiry described in "How We Think" have been presented with a pedagogical purpose and not with a logical one; what is more, they are not "chronological" (Dewey, 1922). In relation to this we would like to add that in his book J. Dewey explicitly points out that the aforementioned steps could be carried out in a sequence different than the suggested one, that they could even be reduced.

The revised version of "How We Think" suggests a new series of steps but keeps the meaning he inferred when describing the unity of thinking and action: suggestions, intellectualization, hypothesis, reasoning, testing the hypothesis in action (Dewey, 1933).

There are some contemporary authors who visualize and describe this series of steps in Dewey's model (see, for example: Miettinen, 2000). There are also authors who analyse the structure of inquiry described in Dewey's book „Logic: The Theory of Inquiry” (see, for example: Brown, 2012). 
In this sense, it is acceptable to say that there is a diversity of contemporary interpretations of Dewey's model of inquiry which can be useful to teachers who intend to plan and implement inquiry-based learning. This simply shows the validity of Dewey's understanding that there is no universal recipe when it comes to thinking.

\section{John Dewey's Model of Reflective Inquiry}

T. Burke makes an important distinction regarding Dewey's concept of inquiry. According to Burke inquiry can be completely perceptive in character by transitioning in an automatic way from problem to solution; but it can also include reflective processes (Burke, 1994). In the first case inquiry equals registering sensory data received as a result of actions completed out of habit or following an algorithm. In the second case, solutions are suggestions (ideas) formulated on the basis of available facts from the point of view of conceptual frames, and the claims for relations between actions and consequences have a good argumentation (Vanderstraeten $\&$ Biesta, 1998).

Dewey's model of reflective inquiry comprises of his reasoning about thinking and reflection (the best way of thinking).

The object of thinking is difficulty, doubt, a problem and its solution. Reflection studies the essence of the problem before moving on to resolving it, it checks the inference and the conclusion - reflection "transforms the simple inference into a tested conclusion; the suggested conclusions into evidence" (Dewey, 1997, p. 74).

Active, persistent, and careful consideration of any belief or supposed form of knowledge in the light of the grounds that support it, and the further conclusion to which it tends, constitutes reflective thought. (ibid, p. 6; Dewey's italics)

Reflection thus implies that something is believed in (or disbelieved), not on its own direct account, but through something else which stands as witness, evidence, proof, voucher, warrant; that is, as ground of belief. (ibid, p. 8; Dewey's italics)

The Bulgarian psychologist V. Vasilev points out that "for Dewey reflection is not only thorough (looked at from all sides) but also a planned, systematic inquiry which has been thought through in advance, inquiry of the subject following its own (of the researcher) subjective logic and technology and not following the logic of the object and circumstances" (Vasilev, 2006, p. 45).

V. Vasilev recognizes two types of reflection in the concept of J. Dewey-intellectual reflection and praxiological reflection. Intellectual reflection is a process of becoming aware of the grounds of knowledge, as well as a process of becoming aware of the methods for attaining knowledge; praxiological reflection is a process of preparation of knowledge for application in practice, the process of transformation of knowledge into instruments of the activity. V. Vasilev describes the unity of intellectual and praxiological reflection as a logical circle of reflexive control (Vasilev, Djaldety, 1990).

Another important peculiarity of Dewey's concept of reflective thinking is the idea that reflective thinking is related to action: reflection is realized during or after the action or consecutively - during and after the action (Figure 3). 
PROBLEMS

OF EDUCATION

IN THE $21^{\text {st }}$ CENTURY

Volume 63,2015

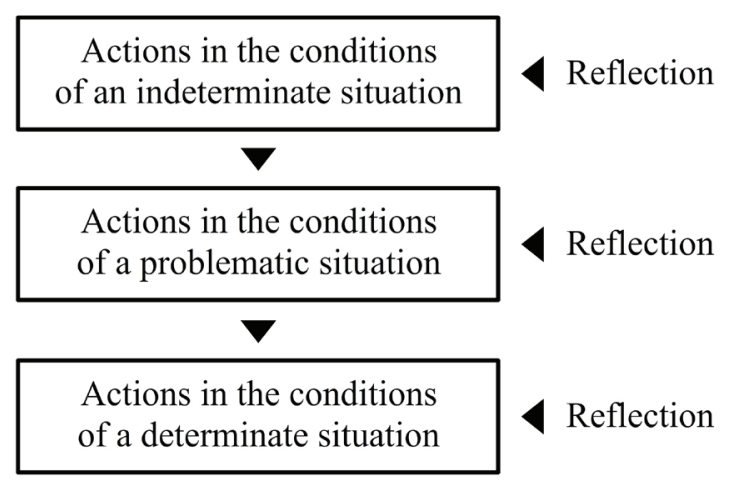

Figure 3: Reflection and action (according to J. Dewey).

J. Dewey describes impulsive or routine action (action completed following a habit, a tradition or a certain authority) and reflective thinking (which includes thinking over of the action itself, the reasons for its completion and the consequences it might cause).

The American philosopher Donald Schön enriches Dewey's idea for the relation between actions and reflection. In his dissertation (1955) D. Schön focuses his attention on Dewey's theory of inquiry (Farrel, 2012) by adding new ideas in his books ,"The Reflective Practitioner" (Schön, 1983)" and "Educating the Reflective Practitioner" (Schön, 1987).

According to D. Schön, in the context of professional practice, knowing and doing are inseparable. That is why, depending on the practical situation, two forms of reflection can occur (Dimova, 2011):

-reflection-on-action, which is directed towards the action which is being carried out but when the action is interrupted (stop-and-think in the pause), or is directed towards the action after it has already been completed;

- reflection-in-action, which is directed towards the action which is being carried out without interrupting the action itself, that is, this is thinking which is in an interactive mode with the action.

We may reflect on action, thinking back on what we have done in order to discover how our knowing-in-action may have contributed to an unexpected outcome. We may do so after the fact, in tranquility, or may pause in the midst of action...

[W]e may reflect in the midst of action, without interrupting it. In an action-present - a period of time, variable with the context, during which we can still make a difference to the situation at hand - our thinking serves to reshape what we are doing while we are doing it. (Schön, 1987, p. 26; Schön's italics)

As a researcher of the action, the practitioner carries out framing/reframing of the problematic situation in terms of their overarching theory, by using their own available repertoire (the repertoire includes examples from their practice, images, understanding, descriptions and practical actions, accessible to them); the practitioner constructs a new understanding of the situation or builds hypotheses (they seek to make the situation), chooses methods for solving the problem that has been established; carries out hypothesis testing experiment in order to verify the hypothesis, while at the same time taking into account the possibility that it may not be confirmed; and in the end re-appreciates the altered practical situation.

The process spirals through stages of appreciation, action, and re-appreciation. The unique and uncertain situation comes to be understood through the attempt to change it, and changed through the attempt to understand it. (Schön, 1983, p. 132)

A successful reframing of the problematic situation leads to a continuation of the reflective conversation. (ibid, p. 136) 
Although there are some critical notes on the differences between the two forms of re-

flection described by Schön, it is safe to say that it is generally accepted that they manifest themselves in reflective practice.

Some authors add yet another form - reflection-for-action. This kind of reflection "is the desired outcome of both previous types of reflection" (Killion \& Todnem, 1991, 15), this is thinking about a reason or a particular purpose, as well as a plan for future actions (Ghaye \& Lillyman, 2006).

\section{Learning Science through Reflective Inquiry}

John Dewey's model of inquiry is quite appropriate for didactic interpretation in the context of Science education because it includes methods of scientific inquiry in the field of Natural Sciences - observation and experiment. This part of the model is very important from a didactic point of view because the method is inseparable from knowledge and the actions related to achieving them.

To attain the goals of Science education the reconstructed model of J. Dewey for learning through reflective inquiry could put an emphasis on reflection on the experiment which includes in itself observation as an inseparable component (Figure 4, 5).

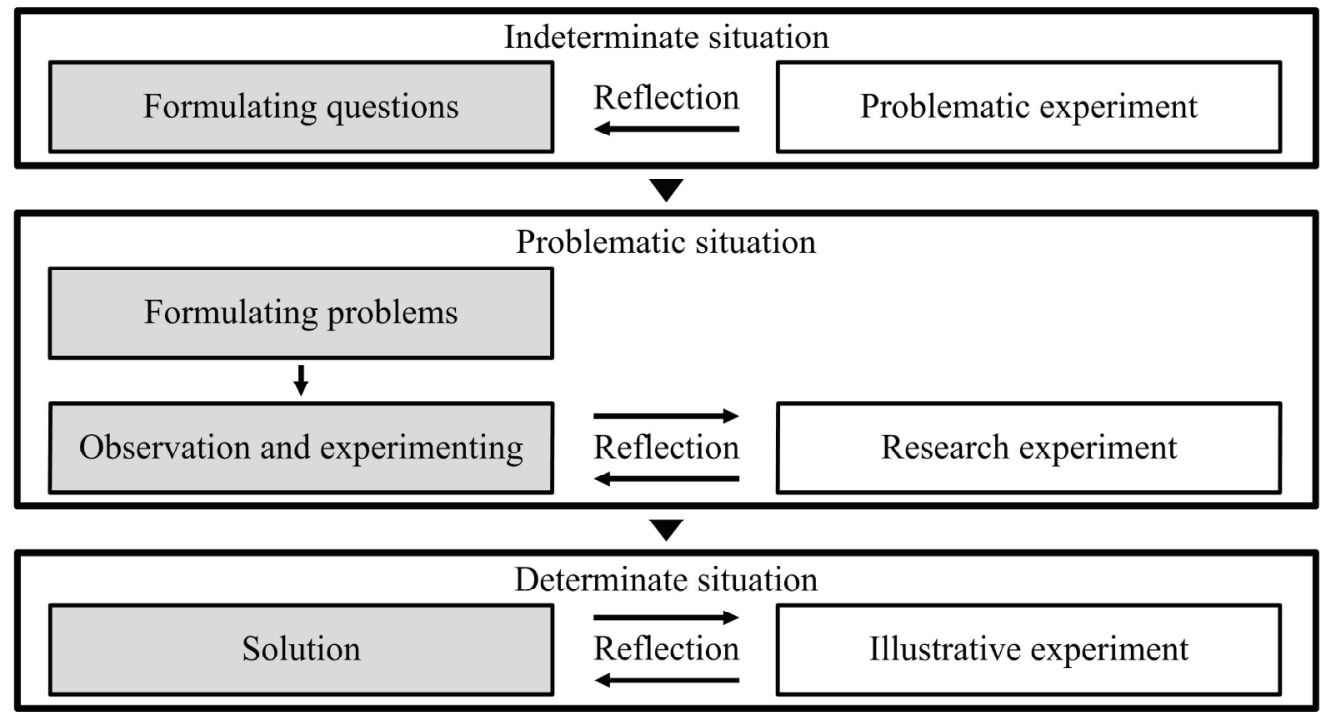

Figure 4: A didactic model of learning through reflective inquiry for beginners 
PROBLEMS

OF EDUCATION

IN THE $21^{\text {st }}$ CENTURY

Volume 63,2015

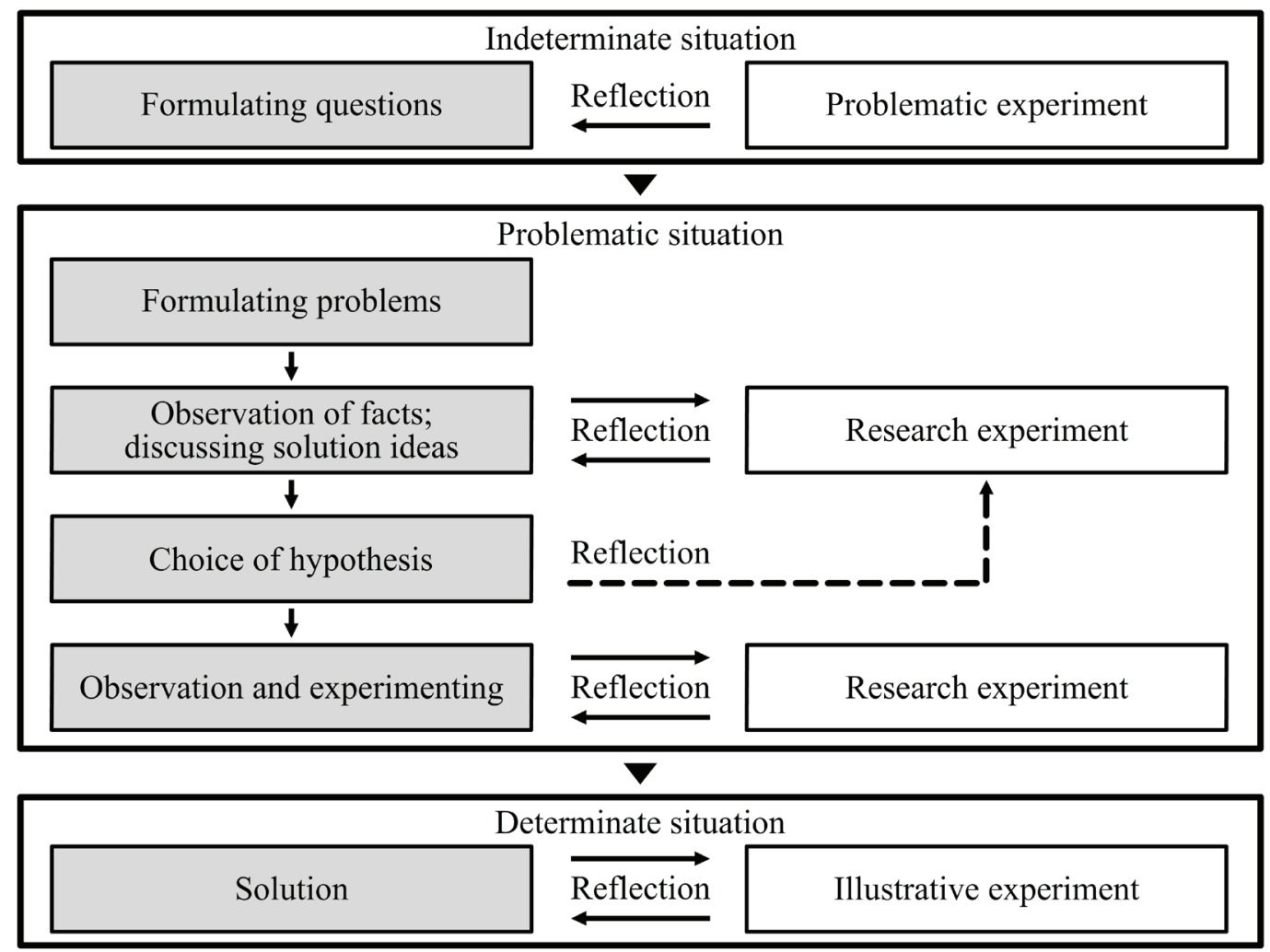

Figure 5: A didactic model of learning through reflective inquiry for advanced learners.

In the core of the didactic model of learning through reflective inquiry lays the experiment since this method reflects the specificity of Science as a study subject as well and because through it empirical and theoretical knowledge is intertwined in a specific way, and it is a known fact that this intertwining presupposes actualizing and activating the mechanisms of reflection in the student.

The problematic experiment should prepare the students for a transition to perceiving a problematic situation; to motivate the necessity of formulating a problem. To realize this goal, the experiment needs to be non-standard and should lack enough data to explain the results from the changes observed in the objects which have been studied (Surin, 2007); to lead to facts whose interpretation requires new structuring of certain information or the addition of new elements to the supporting knowledge of the objects which are studied (Dimova, 2012). Data for getting new knowledge for the objects which are studied is gathered through research experiment. If the research experiment is related to a hypothesis which has been formed in advance, its goal would be to present data confirming or disregarding the hypothesis.

The illustrative experiment might suggest new aspects of applying the knowledge about the objects which are studied.

In the process of conducting the experiment, intellectual reflection for or in action can be actualized by asking the following questions:

What is the goal of the experiment? What means are required to achieve it? Up to what extent the selected means are appropriate for effective completion of the activity?

After completion and accounting for the data from what has been observed during the experiment, reflection on action can be actualized: 
- intellectual reflection - How did you conduct the experiment? What data from the experiment you understand/don't understand? What surprises you? What conclusions did you draw, and why? What do you know about the object(s) that you carried out? What is it that you still don't know about it/them? What more would you like to learn?

- personal reflection - What was most difficult for you/what do you consider your most successful actions? Why? How did you feel during the experiment? What did you learn about yourself/your knowledge and skills during the experiment? What should you improve as far as your actions are concerned?

- reflection-dialogue - Who was the most active person during the conduction and analysis of the experiment? Who was most emotional? Were there any disputes? Were there differences of opinion when formulating the conclusions? Did your classmates take your opinion into consideration? Whom did your classmates take into consideration most often?

- praxiological reflection - What knowledge/skills were necessary to complete the experiment? How could the completion of the experiment be improved? How can the data from the experiment be used? What is required in order to be able to apply the new knowledge/skills in practice?

In the role of didactic means which ensure activating various types of reflection the so called reflective cards can be used. The reflective cards are an effective means for fast but focused reflection on action (Ghaye \& Lillyman, 2006). Various aspects for evaluating the qualities of the activities, of the cognitive and emotional sates of the students can be included in them.

\section{Conclusions}

It is a generally accepted opinion that the value of studying Science through reflective inquiry lies in the opportunity for the student to take on the role of a researcher and from this stand point to realize how the process of science knowledge develops and how knowledge is attained. That is why there is a search for innovative ideas how to operationalize students' reflection for effective implementation of this type of inquiry.

This interpretive framework shows that there is a possibility to draw new didactic ideas for actualizing reflection on the basis of Dewey's model of reflective inquiry.

The authors abandon the generally accepted idea that the stages of reflective thinking are the main element of this model. The emphasis is moved towards the connection between reflection and the actions in the course of the inquiry. This allows for reconstructing Dewey's model as a model of knowing in action in which the methods of observation and experiment stand out.

The reconstructed Dewey's model could facilitate the better understanding of reflective inquiry in Science education practice, could help teachers encourage students to learn actively through reflective inquiry and to enrich their cognitive experience, improve their science literacy.

\section{Acknowledgements}

The authors would like to thank the Reviewer for the constructive notes and valuable suggestions for editing this manuscript.

\section{References}

Barrow, L. (2006). A brief history of inquiry: from Dewey to standards. Journal of Science Teacher Education, 17, 265-278. 
Yordanka DIMOVA, Kalina KAMARSKA. Rediscovering John Dewey's model of learning through reflective inquiry

PROBLEMS

OF EDUCATION

IN THE $21^{\text {st }}$ CENTURY Volume 63, 2015

38

Buermeyer, L. (1920). Professor Dewey's analysis of thought. The Journal of Philosophy, Psychology and Scientific Methods, 17 (25), 673-681.

Burke, T. (1994). Dewey's New Logic: a reply to Russell. Chicago: The University of Chicago Press.

Brown, M. (2012). John Dewey's logic of science. HOPOS: The Journal of the International Society for the History of Philosophy of Science, 2 (2), 258-306.

Dewey, J. (1997 / 1910). How we think. New York: Dover Publications, Inc.

Dewey, J. (1922). An analysis of reflective thought. The Journal of Philosophy, 19 (2), 29-38.

Dewey, J. (1929). The quest for certainty: a study of the relation of knowledge and action; New York: Minton, Balch \& Company.

Dewey, J. (1933). How we think: a restatement of the relations of reflective thinking to the educative process. Boston: D.C. Heath \& Co.

Dewey, J. (1938). Logic - the theory of inquiry. New York: Henry Holt and Company.

Dimova, Y. (2011). Reflective approach to education: from concepts of reflection to a model of reflective practice. Saarbrücken: LAP LAMBERT Academic Publishing GmbH \& Co. KG.

Dimova, Y. (2012). Study chemical experiment and active learning. In: Epitropova, A., Dimova, Y., Kamarska, K. Active learning in science education. Plovdiv: University Publishing House "P. Hilendarski", 48-72, 2012. [In Bulgarian].

Farrel, T. (2012). Reflecting on reflective practice: (Re) Visiting Dewey and Schon. TESOL Journal, 3 (1), 7-16.

Ghaye, T., \& Lillyman, S. (2006). Reflection \& writing a reflective account. Institute of Reflective practice-UK. [CD-ROM].

Gormally, C., Brickman, P., Armstrong, N., Hallar, B. (2009). Effects of inquiry-based learning on students' science literacy skills and confidence. International Journal for the Scholarship of Teaching and Learning, 3 (2), Article 16.

Jones, J., \& Jones, K. (2013). Teaching reflective practice: Implementation in the teacher-education Setting. Teacher Educator, 48 (1), 73-85.

Kamarska, K., Uzova, D., Golechova, M. (2014). Results from experimental education in the methodology of reflective inquiry of chemical objects ( $6^{\text {th }}$ grade). Chemistry: Bulgarian Journal of Science Education, 23 (1), 88-97. [In Bulgarian].

Killion, J., \& Todnem, G. (1991). A process for personal theory building. Educational Leadership, 48 (6), 14-16.

Kolb, D. (1984). Experiential learning experience as the source of learning and development. New Jersey: Prentice-Hall, Inc.

Krishnamurthy, S. (2007). Reflexive inquiry and reflective practice: Critical reflection and pedagogy in english language teaching. Nawa: Journal of Language and Communications, 1 (2), 14-22.

Lyons, N. (Ed.), (2010). Handbook of reflection and reflective inquiry. Mapping a way of knowing for professional reflective inquiry. New York: Springer.

Mason, J. (2012). Scaffolding reflective inquiry - enabling why-questioning while e-learning. Research and Practice in Technology Enhanced Learning, 7 (3), 175-198.

Miettinen, R. (2000). The concept of experiential learning and John Dewey's theory of reflective thought and action. International Journal of Lifelong Education, 19 (1), 54-72.

Minchev, B. (2008). General psychology. Sofia: Ciela. [In Bulgarian]

Oliver, C. (2004). Reflexive inquiry and the strange loop tool. Human Systems: The Journal of Systemic Consultation \& Management, 15 (2), 127-140.

Rodgers, C. (2002). Defining reflection: Another look at John Dewey and reflective thinking. Teachers College Record, 104 (4), 842-866.

Sahin, F., \& Usta Gezer, S. (2014). The effects of reflective inquiry based activities' on preservice science teachers' biology laboratory concerns and critical thinking dispositions. The Journal of SAU Education Faculty, 27 (May), 25-50.

Schön, D. (1983). The reflective practitioner: how professionals think in action. New York: Basil Books.

Schön, D. (1987). Educating the reflective practitioner. San Francisco: John Wiley and Sons, CA.

Surin, U. (2007). The problematic experiment as a type of chemical experiment. Himiya v Shkole, 10, 57-61. [In Russian].

Vanderstraeten, R., Biesta, G. (1998). Education, diversity, and constructivism: A pragmatic point of view. Presented at the Annual Meeting of the American Educational Research Association, San Diego, CA, April 13-17. 
Vasilev, V. (2006). Reflection in knowledge, self-knowledge and practice. Plovdiv: Macros. [In Bulgarian]

Vasilev, V., \& Djaldety A. (1990). Phenomenological characteristics and logical argumentation of praxiological reflection. Reflection, Activity, Culture, 27 (2), 13-19.

Won, M. (2009). Issues in inquiry-based science education seen through Dewey's theory of inquiry. Dissertation. University of Illinois, Urbana, Illinois.

Advised by Elena Guergova, University of Plovdiv "Paisii Hilendarski”, Plovdiv, Bulgaria

Received: January 11, 2015

Accepted: February 26, 2015

Yordanka Dimova PhD, Associate Professor, University of Plovdiv "Paisii Hilendarski", 24 Tzar Asen Str., Plovdiv - 4000, Bulgaria.

E-mail: dimova@uni-plovdiv.bg

Kalina Kamarska PhD Student, University of Plovdiv "Paisii Hilendarski", 24 Tzar Asen Str. Plovdiv - 4000, Bulgaria.

E-mail: kamarska@uni-plovdiv.bg 